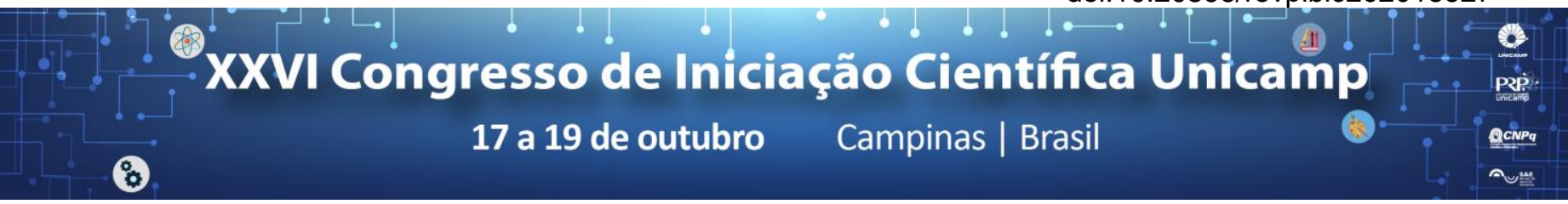

\title{
Desenvolvimento de uma Plotter (CNC) XYZ para implementação de conceitos de controle e automação visando uso em projetos futuros.
}

\section{Gidiones L. Nobrega*, Joao V. d'Abreu, Juan Victor T. Pessoa.}

\section{Resumo}

Este projeto tem como objetivo o desenvolvimento de Conceitos de Controle e Automação utilizando como plataforma o Comando Númerico Computadorizado(CNC) aplicado a um plotter XYZ, visando o uso futuro dos métodos e princípios adquiridos para auxiliar em outros projetos de robótica e automação que necessitem de uma movimentação precisa e controlada.

\section{Palavras-chave: \\ Comando Númerico Computadorizado(CNC), Róbotica Educacional, Controle e Automação.}

\section{Introdução}

O Controle e a Automação e mais especificamente a robótica são conceitos que resumem a utilização de tecnologias para tornar autônomas e controladas determinadas ações e processos, sendo amplamente utilizado em diversas áreas como a industrial, educacional e tecnológica. Nesses ramos o controle de movimentos merece destaque e é um dos principais focos de atuação da automação. Esse tipo de controle é obtido a partir da aquisição de dados por meio de sensores e uso dos dados coletados para coordenar atuadores específicos ${ }^{1}$, através de uma unidade controladora. As diversas áreas citadas fazem uso desse controle: a indústria mecânica e eletrônica em máquinas de fabricação e montagem; a tecnológica em impressoras 3D e equipamentos de medições; e a educacional no uso da lógica e programação desses equipamentos. Um sistema muito utilizado no controle de movimentos é o Comando Numérico Computadorizado (CNC) que utiliza microcomputadores e uma interface via software que permite o usuário programar e controlar máquinas. $^{2}$ Atualmente no mercado existe uma variedade de exemplos que utilizam esse tipo de sistema. Entretanto por questões de simplicidade e didática, utilizaremos como plataforma de estudo do CNC um plotter XYZ por esse abranger os mesmos métodos e conceitos de equipamentos mais sofisticados.

\section{Resultados e Discussão}

Uma versão artesanal de um plotter $X Y Z$, foi construída Fig.1 juntamente com um driver de controle para os motores - Fig.2, utilizou-se como unidade controladora um microcontrolador Arduino uno e realizaram-se alguns testes, entretanto ocorreram diversos problemas de montagem e alinhamento, que restringiam a velocidade e a força dos movimentos. Logo está em desenvolvimento uma nova versão com componentes projetados e fabricados sobre precisão para corrigir os erros encontrados. Para o projeto mecânico está sendo utilizado o software de CAD Solid Edge da Siemens por ser um freeware com funcionalidades avançadas de simulação e montagem de peças. E a fabricação se dará mediante parceria com o Laboratório de Ensaios Dinâmicos da Unicamp (LabEDin).
Figura 1. Versão artesanal do Plotter XYZ.

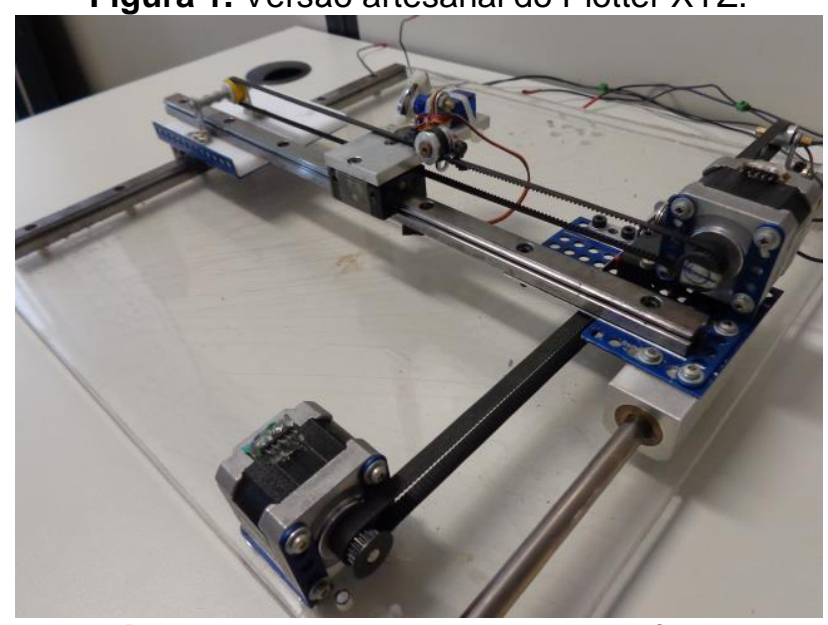

Figura 2. Driver de controle construído.

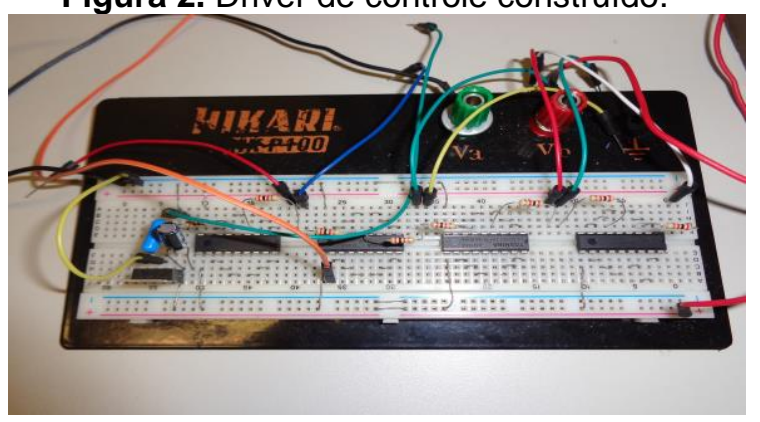

\section{Conclusões}

O projeto se encontra em fase de prototipagem, modelagem tridimensional de peças e de aquisição de materiais e componentes eletrônicos e mecânicos para sua finalização.

\section{Agradecimentos}

Agradecimentos ao Sistema de Apoio ao Estudante (SAE) - Unicamp, pelo fomento das bolsas (BAS).

Agradecimentos ao Prof.- Pablo Siqueira pelo suporte e infraestrutura oferecido pelo Laboratório de Ensaios Dinâmicos (LabEDin) o qual coordena.

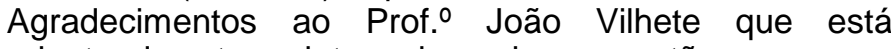
orientando este projeto, pelo apoio e sugestões.

${ }^{1}$ DORF, Richard C; BISHOP, Robert H. Sistemas de controle modernos - 8.ed / 2001 8.ed. Rio de Janeiro, RJ: Livros Técnicos e Científicos, 2001.

${ }^{2}$ IFAO,1984 - IFAO Institut für angewandte Organisationsforschung; Comando

Numérico CNC -Técnica Operacional Torneamento; 1984; Editora EPU. 